\title{
Gadolinium Inhibits Mechanoelectrical Transduction in Rabbit Carotid Baroreceptors Implication of Stretch-activated Channels
}

George Hajduczok, Mark W. Chapleau, Randolph J. Ferlic, Hui Z. Mao, and Francois M. Abboud

The Cardiovascular Center and the Departments of Internal Medicine, and Physiology and Biophysics, University of Iowa College of Medicine, and the Department of Veterans Affairs Medical Center, Iowa City, Iowa 52242

\begin{abstract}
Gadolinium $\left(\mathrm{Gd}^{3+}\right)$ has been shown to prevent mechanoelectrical transduction believed to be mediated through stretch-activated channels. We investigated the possible role of $\mathbf{G d}^{3+}$-sensitive channels in mediating baroreceptor activity in the carotid sinus of rabbits. Baroreceptor activity induced by a ramp increase of carotid sinus pressure was reduced significantly during exposure to $\mathrm{Gd}^{3+}$. The inhibition was dose-related and reversible, and was not associated with alteration of carotid sinus wall mechanics as the pressure-strain relationship was unaffected. Veratrine triggered action potentials from single- and multiple-baroreceptor fibers when their response to pressure was inhibited by $\mathrm{Gd}^{3+}$. This suggests that the effect of $\mathrm{Gd}^{3+}$ on baroreceptors in the isolated carotid sinus was specific to their mechanical activation. The results suggest that stretch-activated ion channels sensitive to $\mathrm{Gd}^{3+}$ may be the mechanoelectrical transducers of rabbit carotid sinus baroreceptors. (J. Clin. Invest. 1994. 94:2392-2396.) Key words: baroreceptor • mechanotransduction • stretch-activated ion channels • sensory neurons $\cdot$ cardiovascular
\end{abstract}

\section{Introduction}

Arterial baroreceptors are activated during increases in transmural pressure $(1,2)$. Activation of these receptors occurs as a result of mechanical deformation through stress and strain of the arterial wall. This mechanical deformation is transduced into an electrical depolarization of the nerve ending, triggering action potentials at the spike initiating zone. The mechanoelectrical transduction mechanism for the activation of arterial baroreceptors, however, is not clear. Several mechanisms for the mechanosensory process have been proposed including chemical, osmotic, or channel linked (3-5). More recent studies have demonstrated the presence of ion channels sensitive to

Address correspondence to Francois M. Abboud, MD, Edith King Pearson Professor \& Head, Department of Internal Medicine, SE $308 \mathrm{GH}$, University of Iowa, Iowa City, IA 52242. George Hajduczok's present address is Department of Physiology, SUNY at Buffalo School of Medicine and Biomedical Sciences, Buffalo, NY 14214. Randolph J. Ferlic's present address is Department of Orthopedic Surgery, University of Wisconsin Medical Center, Madison, WI 53792. 1994.

Received for publication 15 April 1994 and in revised form 19 July

1. Abbreviations used in this paper: CSP, carotid sinus pressure; $\mathrm{P}_{\mathrm{th}}$, pressure threshold; SA, stretch activated.

The Journal of Clinical Investigation, Inc.

Volume 94, December 1994, 2392-2396 stretch $(6,7)$. These stretch-activated $(\mathrm{SA})^{1}$ ion channels have subsequently been identified in a number of vertebrate tissues, as well as invertebrates and plants $(8,9)$.

The identification of this type of channel has led to the proposal that the basic mechanoelectrical transduction mechanism for sensory mechanoreceptors may be mediated through SA ion channels. It is not known whether activation of cardiovascular mechanoreceptors involves SA ion channels. Most studies have used single channel or whole cell recording techniques to determine the presence or absence of SA ion channels (10-15). Cardiovascular mechanoreceptor endings are located within the walls of the heart and blood vessels $(1,2)$ and are virtually inaccessible to single cell electrophysiological approaches in intact preparations. Yang and Sachs (13) have shown the trivalent lanthanide, gadolinium $\left(\mathrm{Gd}^{3+}\right)$, to be a specific blocker of SA ion channels in Xenopus oocytes and $\mathrm{Gd}^{3+}$ has since been reported to block SA ion channels in other tissues (15-17). Very recently, Naruse and Sokabe (18) reported blockade of SA ion channels in endothelial cells by $\mathrm{Gd}^{3+}$. These studies were undertaken to determine whether SA ion channels are present on arterial baroreceptor nerve endings in situ using $\mathrm{Gd}^{3+}$ as a probe for this new class of ion channel.

\section{Methods}

New Zealand white rabbits $(1.5-2.5 \mathrm{~kg})$ of either sex were anesthetized with sodium pentobarbital ( $25-30 \mathrm{mg} / \mathrm{kg}$, i.v.). Supplemental doses of sodium pentobarbital ( $10-15 \mathrm{mg} / \mathrm{kg}$, i.v.) were administered hourly. The rabbits were mechanically ventilated (Harvard Apparatus Inc., South Natick, MA) with room air supplemented with $100 \% \mathrm{O}_{2}$ through a tracheostomy. The tidal volume and frequency of the ventilator were adjusted to maintain arterial $\mathrm{PCO}_{2}$ between 30 and $40 \mathrm{mmHg}$. Sodium bicarbonate was administered when necessary in order to maintain arterial $\mathrm{pH}$ between 7.35 and 7.45. Catheters were placed in a femoral artery and vein for measurement of arterial pressure and administration of anesthetic, respectively. All procedures were in accordance with federal and institutional guidelines.

Isolated carotid sinus preparation. The left or right carotid sinus was vascularly isolated as described previously $(19,20)$. All visible branches of the common and external carotid arteries were ligated. Catheters were positioned in the common and external arteries and the internal carotid artery was ligated. The isolated sinus was flushed and filled with physiologic salt solution $\left(38^{\circ} \mathrm{C}\right)$ equilibrated with $95 \% \mathrm{O}_{2^{-}}$ $5 \% \mathrm{CO}_{2}$ of the following composition $(\mathrm{mM}): \mathrm{NaCl} 98.0, \mathrm{KCl} 4.7$, $\mathrm{NaHCO}_{3} 24.0, \mathrm{KH}_{2} \mathrm{PO}_{4}$ 1.1, $\mathrm{MgSO}_{4} 1.2, \mathrm{CH}_{3} \mathrm{COONa} 20.0, \mathrm{CaCl}_{2} 2.5$, and glucose 10.0. The $\mathrm{PO}_{2}$ of the solution ranged between 100 and 300 $\mathrm{mmHg}, \mathrm{PCO}_{2}$ ranged between 30 and $40 \mathrm{mmHg}$, and the $\mathrm{pH}$ ranged between 7.35 and 7.45. The carotid sinus was connected to a pressure reservoir via the common carotid artery and carotid sinus pressure was measured through the external carotid artery with a transducer (P23IA; Statham Instruments, Hato Rey, PR). $\mathrm{Gd}^{3+}$ (Aldrich Chemical Co., Milwaukee, WI) and veratrine (Sigma Chemical Co., St. Louis, MO) were diluted to the desired concentration in physiological salt solution just before use. The solution in the sinus was changed frequently at least once with every concentration of $\mathrm{Gd}^{3+}$ and during recovery. 


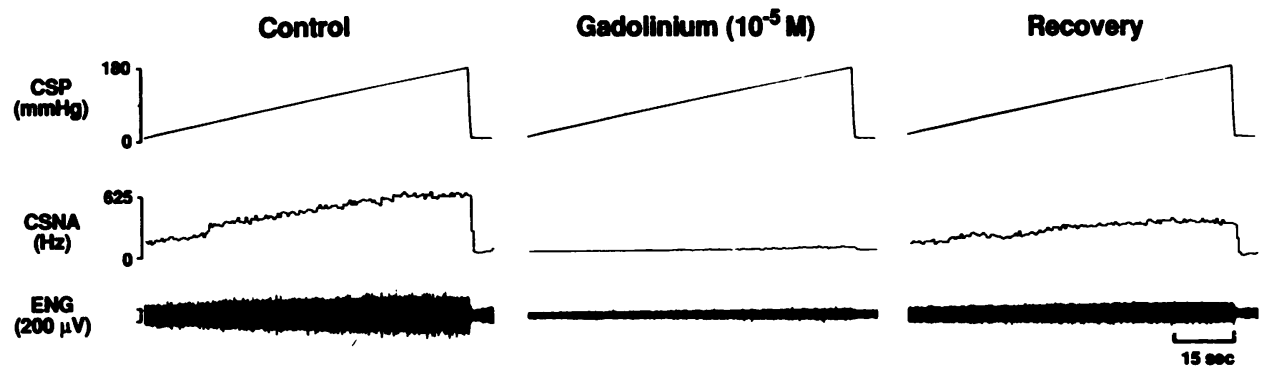

Figure 1. A ramp increase in carotid sinus pressure (CSP) increased mean carotid sinus nerve activity (CSNA) and the nerve activity seen on the electroneurogram (ENG) in the control condition. $\mathrm{Gd}^{3+}$ blocked the increase in nerve activity during a similar pressure ramp. After removal of $\mathrm{Gd}^{3+}$, nerve activity was restored.

We occasionally noted that $\mathrm{Gd}^{3+}$ at a concentration of $1 \mathrm{mM}$ turned our bicarbonate-buffered physiological salt solution cloudy. Andresen and Yang (21) also described this precipitation at concentrations $>500$ $\mu \mathrm{M}$ in Krebs solution, possibly as the result of $\mathrm{Gd}^{3+}$ complexing with bicarbonate or phosphate anions. We performed additional experiments, using a Hepes-buffered salt solution of the following composition $(\mathrm{mM}): \mathrm{NaCl}, 140 ; \mathrm{KCl}, 6 ; \mathrm{MgSO}_{4}, 1.2 ;$ glucose, $5.5 ; \mathrm{CaCl}_{2}, 1.1$; and Hepes, $10 \mathrm{mM}$. In the first group of experiments with $\mathrm{Gd}^{3+}$ in physiological salt solution, the duration of exposure necessary to inhibit baroreceptor activity ranged from 20 to $130 \mathrm{~min}$. Because of the length of the study and our success in avoiding precipitation of $\mathrm{Gd}^{3+}$ at high concentration with $\mathrm{Gd}^{3+}$ in Hepes we elected to standardize the exposure time to $\sim 30 \mathrm{~min}$ in the second group of experiments. The results reported were those in which inhibition was observed during the period of exposure to $\mathrm{Gd}^{3+}$.

The gas tensions and $\mathrm{pH}$ were also measured from the Hepes-buffered solutions sampled from the carotid sinus at a time when baroreceptor nerve activity was measured during the control period or when inhibited by $\mathrm{Gd}^{3+}$. There was no significant decline in $\mathrm{PO}_{2}$ or $\mathrm{PCO}_{2}$ during the period of exposure to $\mathrm{Gd}^{3+} \cdot \mathrm{Po}_{2}$ and $\mathrm{PCO}_{2}$ averaged $149 \pm 10$ and $8 \pm 1 \mathrm{mmHg}$, respectively, during control $(n=5) ; 133 \pm 6$ and $7 \pm 1$ $\mathrm{mmHg}$ during $10^{-4} \mathrm{M} \mathrm{Gd}^{3+}(n=7)$; and $139 \pm 6$ and $7 \pm 1 \mathrm{mmHg}$ during $10^{-3} \mathrm{M} \mathrm{Gd}^{3+}(n=7)$.

The $\mathrm{pH}$ of the Hepes-buffered salt solution sampled from the carotid sinus averaged $7.320 \pm 0.017(n=5)$. In the first two experiments we noted that the high concentration of $\mathrm{Gd}^{3+}\left(10^{-3} \mathrm{M}\right)$ decreased the $\mathrm{pH}$ of the Hepes solution sampled from the carotid sinus from 7.371 and 7.305 to 7.076 and 7.069 , respectively. Therefore, in subsequent experiments the $\mathrm{pH}$ of a $10^{-3} \mathrm{M} \mathrm{Gd}^{3+}$ stock solution was adjusted to near 7.4 with $\mathrm{NaOH}$. In these experiments the $\mathrm{pH}$ of the $10^{-3} \mathrm{M} \mathrm{Gd}^{3+}$ solution sampled from the sinus averaged 7.302 $\pm 0.010(n=5)$. The lower concentrations of $\mathrm{Gd}^{3+}$ did not alter the $\mathrm{pH}$ in any of the experiments. The $\mathrm{pH}$ of the $10^{-4} \mathrm{M} \mathrm{Gd}^{3+}$ solution sampled from the sinus averaged $7.311 \pm 0.011(n=7)$.

Temperature in the sinus was maintained at $38^{\circ} \mathrm{C}$ by a combination of approaches including warming the solutions, the animal, and the sinus region (19).

Measurement of carotid sinus nerve activity. The carotid sinus nerve was cut at its junction with the glossopharyngeal nerve and placed on bipolar platinum electrodes $(19,20)$. The nerve and electrodes were encased in Silgel 604 (Wacker Silicones Corp., Adrian, MI) and the sinus region was bathed externally with physiological saline or paraffin oil. Multiunit carotid sinus nerve activity was recorded using a high impedance probe (HIP511E) and a preamplifier (P511; low frequency cut-off $30 \mathrm{~Hz}$; high frequency cut-off 3-10 kHz; both from Grass Instrument Co., Quincy, MA). The electroneurogram was displayed on a dual-beam storage oscilloscope (model 5113; Tektronix Inc., Beaverton, OR) and monitored with a loud speaker. A nerve traffic analyzer (model 706C; University of Iowa Bioengineering, Iowa City, IA ) counted action potentials that exceeded a selected voltage via a window discriminator. Before recording nerve activity, decamethonium bromide (Syncurine; ICU-K\&K Laboratories, Cleveland, $\mathrm{OH} ; 0.3 \mathrm{mg} / \mathrm{kg}$ ) was administered to each rabbit to prevent muscular movement. Carotid sinus pressure, systemic arterial pressure, integrated spike counts, and mean and raw nerve activities were continuously displayed on an electrostatic recorder (model ES1000; Gould Inc., Cleveland, OH).
Measurement of carotid sinus diameter. The diameter of the carotid sinus was measured with sonomicrometer crystals $(19,20)$. A low resistance, stainless steel clip holding two miniature piezoelectric crystals $(5 \mathrm{MHz})$ was placed across the carotid sinus and sutured to the adventitia. The diameter of the sinus was determined from the transit time of acoustic signals between crystals.

Pressure-baroreceptor activity relation. Baroreceptor activity was recorded during slow ramp increases $(<3 \mathrm{mmHg} / \mathrm{s})$ in pressure in the isolated carotid sinus from 0 to $160 \mathrm{mmHg}$. The pressure in the reservoir connected to the sinus was increased by allowing air from a pressurized air tank to flow into the reservoir through a manually regulated sensitive valve $(19,20)$. Before each ramp, carotid sinus pressure was held constant at a level between 20 and $80 \mathrm{mmHg}$.

A minimum of three control ramps were performed before the administration of $\mathrm{Gd}^{3+}$. There were no differences in the pressure-activity relations obtained during the control period. $\mathrm{Gd}^{3+}$ was then placed inside and around the carotid sinus (or strictly inside the sinus in the experiments using Hepes solutions) and the pressure ramp was applied at intervals of $5 \mathrm{~min}$ or longer. $\mathrm{Gd}^{3+}$ was removed from the carotid sinus by thoroughly flushing the inside and outside of the sinus with either salt solution, and recovery responses to the pressure ramp were then obtained.

In five experiments, carotid sinus nerve activity was measured before and after intrasinus administration of veratrine dissolved in physiological saline $(0.125 \mu \mathrm{g} / \mathrm{ml})$ either in the presence or in the absence of $\mathrm{Gd}^{3+}$.

Pressure-diameter relation. The diameter of the carotid sinus was recorded during slow ramp increases in carotid sinus pressure similar to that described above for the pressure-activity relation. The effects of $\mathrm{Gd}^{3+}$ dissolved at various concentrations in physiological saline on the pressure-diameter relation of the carotid sinus were determined as described above for the nerve recording experiments. Carotid sinus wall strain was calculated by the following equation: strain $=\left(d-d_{0}\right) / d_{0}$, where $d_{0}$ represents the initial diameter at carotid sinus pressure (CSP) of $20 \mathrm{mmHg}$, and $d$ is the diameter at any given carotid sinus pressure $(19,20)$.

Data analysis. Baroreceptor activity and carotid sinus diameter were plotted as a function of increases in carotid sinus pressure. Pressure, diameter, and the electroneurogram were recorded and stored on VHS
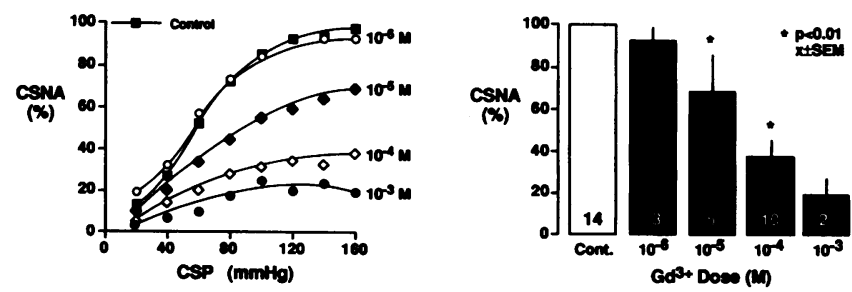

Figure $2 . \mathrm{Gd}^{3+}$ produces a dose-dependent inhibition of the CSNA during ramp increases of CSP. Studies performed using bicarbonate buffered salt solution. Pressure-activity relation at different doses of $\mathrm{Gd}^{3+}$ (left). Bar graph shows a progressive decline of maximal nerve activity during increasing doses of $\mathrm{Gd}^{3+}$ (right). The number in each bar represents the number of experiments (Cont., control). 


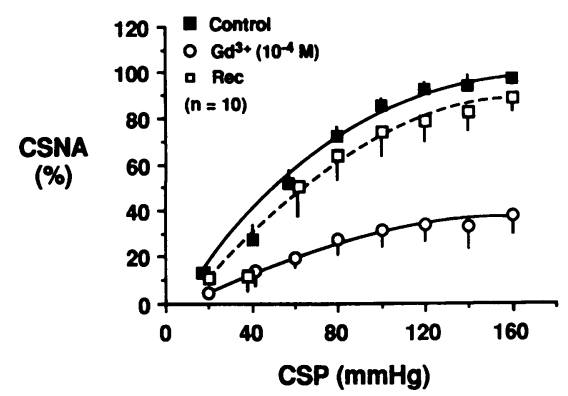

Figure 3. Pressure-activity relation showing that $\mathrm{Gd}^{3+}$ reversibly inhibits baroreceptor activity during the pressure ramp (left). The inhibition occurred without a change in carotid sinus pressure (CSP) - strain relationship (right). Studies performed using bicarbonate-buffered salt solution (Rec., recovery). tape (model 4000PCM digital processor; A.R. Vetter Co., Inc., Rebersburg, PA) for off-line analysis. The output from the tape was also digitized by microcomputer (IBM, Boca Raton, FL) at 10-ms intervals. Statistical analysis was performed using analysis of variance and Fisher's protected least significant difference post hoc test for multiple comparisons (22). Values of $P<0.05$ were considered significant. Results are expressed as mean \pm SEM.

\section{Results}

Baroreceptor activity, induced by ramp increases in carotid sinus pressure, was reduced significantly in a dose-related manner following exposure to $\mathrm{Gd}^{3+}$ (Figs. 1 and 2 ). The time necessary for blockade varied from 20 to $130 \mathrm{~min}$ (mean $=54 \pm 6 \mathrm{~min}$; $n=20$ ). The activity recovered following withdrawal of $\mathrm{Gd}^{3+}$ (Fig. 3). Gd ${ }^{3+}$ did not alter the pressure-strain relationship of the carotid sinus (Fig. 3 ).

Since $\mathrm{Gd}^{3+}$ tended to precipitate in solution at higher concentrations in those experiments, additional studies were done with a Hepes-buffered salt solution in the absence of bicarbonate and phosphate. When $\mathrm{Gd}^{3+}$ was dissolved into this solution, no precipitate was evident at any concentration. Fig. 4 shows a reversible inhibition of baroreceptor activity by $\mathrm{Gd}^{3+}$. Inhibition of baroreceptor activity was observed within 20-30 min $($ mean $=28 \pm 2 \mathrm{~min})$.

In four experiments, two without added $\mathrm{Gd}^{3+}$ and two in the presence of $\mathrm{Gd}^{3+}\left(10^{-4} \mathrm{M}\right)$, we contrasted the effects of veratrine $(0.125 \mu \mathrm{g} / \mathrm{ml})$ and the increase in carotid sinus pressure from 20 to $40 \mathrm{mmHg}$ on the activity of the carotid sinus nerve. The results in Table I show the selective inhibition of nerve activity during the increase in carotid sinus pressure but not with veratrine after $\mathrm{Gd}^{3+}$. An example of the veratrineinduced increase in carotid sinus nerve activity in the presence of $\mathrm{Gd}^{3+}$ is shown in Fig. 5.
In a single baroreceptor fiber, we determined the pressure threshold $\left(\mathrm{P}_{\mathrm{th}}\right)$ which coincided with the onset of action potentials with ramp increases in carotid sinus pressure at $10 \mathrm{~min}$ intervals before and during exposure to $\mathrm{Gd}^{3+}\left(10^{-4} \mathrm{M}\right)$. Carotid sinus pressure was maintained at $20 \mathrm{mmHg}$ in between each pressure ramp to prevent resetting. Before $\mathrm{Gd}^{3+}$ the $\mathrm{P}_{\mathrm{th}}$ approximated $25 \mathrm{mmHg}$. $\mathrm{Gd}^{3+}$ increased $\mathrm{P}_{\text {th }}$ gradually over $2 \mathrm{~h}$ and then more rapidly at $150 \mathrm{~min}$ to a $\mathrm{P}_{\mathrm{th}}$ of $44 \mathrm{mmHg}$ (Fig. $6 \mathrm{~A}$ ). However, the addition of veratrine in the continued presence of $\mathrm{Gd}^{3+}$ triggered activity at a pressure level far below the $\mathrm{P}_{\mathrm{th}}$ for activation of baroreceptors (i.e., $20 \mathrm{mmHg}$ ) (Fig. $6 \mathrm{~B}$ ).

\section{Discussion}

Stretch-activated ion channels are reasonable candidates as mechanoelectrical transducers in several cell types (10-12). $\mathrm{Gd}^{3+}$ has been shown by several investigators to block mechanosensitive ion channels in different preparations or cell systems $(13,15-18)$. We therefore tested the possibility that $\mathrm{Gd}^{3+}$ sensitive SA ion channels may be important for mechanoelectrical transduction in baroreceptors.

Many cells may be sensitive to mechanical deformation, however, the primary function of baroreceptor neurons is inherent in their sensitivity to changes in pressure and strain. Our results indicate that $\mathrm{Gd}^{3+}$ blocks significantly and reversibly, in a dose-related manner, arterial baroreceptor activity. The blockade was not caused by a change of the mechanical behavior of the carotid sinus, since the pressure-strain relationship was unaltered in the presence of $\mathrm{Gd}^{3+}$. Therefore, the inhibition can be ascribed to an effect of $\mathrm{Gd}^{3+}$ on the nerve endings themselves. However, we cannot entirely rule out the possibility of a localized mechanical effect of $\mathrm{Gd}^{3+}$ on the tissue surrounding the terminals that is undetectable with our measurement of the stress-strain relationship of the carotid sinus.
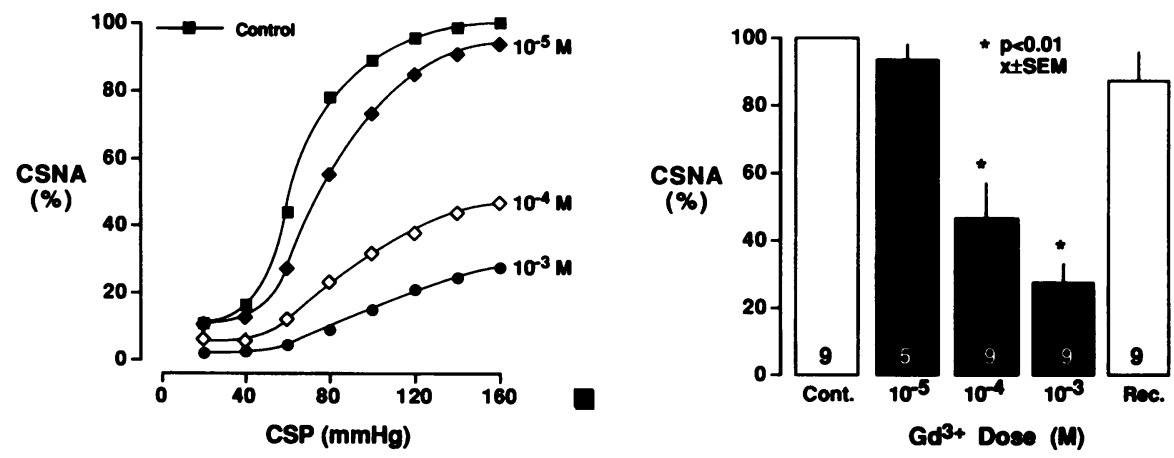

Figure 4. Inhibition of CSNA by $\mathrm{Gd}^{3+}$ during ramp increase of CSP. Studies were performed on 14 isolated sinuses using Hepesbuffered salt solution. The values are those in which $\mathrm{Gd}^{3+}$ reduced activity during the period of exposure $(\sim 30 \mathrm{~min}$ at each dose $)$. Pressure-activity relation at different doses of $\mathrm{Gd}^{3+}$ (left). Bar graph shows progressive decline of maximal nerve activity during increasing doses of $\mathrm{Gd}^{3+}$ (right). The number in each bar represents the number of experiments. The results were obtained from three experiments in which $10^{-3} \mathrm{M} \mathrm{Gd}^{3+}$ decreased the $\mathrm{pH}$ of the Hepes buffer and from six

experiments in which the $\mathrm{pH}$ was adjusted to normal with $\mathrm{NaOH}$. The inhibitory influence of $\mathrm{Gd}^{3+}$ on baroreceptor activity was evident regardless of the $\mathrm{pH}$ so the results were pooled ( $n=9$ ) (Cont., control; Rec., recovery). 
Table I. Percentage Increase in Multifiber Baroreceptor Activity with Increase in Carotid Sinus Pressure from 20 to $40 \mathrm{mmHg}$ and with Addition of Veratrine at $20 \mathrm{mmHg}$

\begin{tabular}{|c|c|c|c|c|c|}
\hline & \multicolumn{2}{|c|}{ No $\mathrm{Gd}^{3+}$} & & \multicolumn{2}{|c|}{$\mathrm{Gd}^{3+}\left(10^{-4} \mathrm{M}\right)$} \\
\hline & CSP & Veratrine & & CSP & Veratrine \\
\hline & \multicolumn{2}{|c|}{$\%$} & & \multicolumn{2}{|r|}{$\%$} \\
\hline Experiment 1 & 122 & 81 & Experiment 3 & 2 & 562 \\
\hline Experiment 2 & 86 & 88 & Experiment 4 & 12 & 135 \\
\hline
\end{tabular}

Also, baroreceptor activity was inhibited with $\mathrm{Gd}^{3+}$ dissolved in either bicarbonate or Hepes-buffered salt solution, so the action of $\mathrm{Gd}^{3+}$ cannot be simply ascribed to a complex interaction of $\mathrm{Gd}^{3+}$ with anions in solution and thereby reducing the free activity of ions which regulate baroreceptor activation.

Although the carotid sinus contains a mixture of baroreceptor and chemoreceptor fibers (2), we believe that in this preparation, the nerve activity was primarily baroreceptor in origin. The vascular isolation of the carotid sinus involves the ligation of the occipital artery to eliminate access to the carotid body. Arterial chemoreceptors are typically activated by decreases in oxygen and $\mathrm{pH}$ and increases in $\mathrm{CO}_{2}$. The preparation was such that the gases of the physiologic salt solution and the frequent changes of solutions throughout the study would minimize any potential stimulation of chemoreceptors ( see Methods). In addition, we tested for the presence of chemoreceptor activity by exposing the carotid sinus to a hypercapnic physiologic salt solution $\left(\mathrm{P}_{\mathrm{CO}_{2}}>600 \mathrm{mmHg}, \mathrm{pH}=6.1\right)$ and were unable to elicit an increase in carotid sinus nerve activity $(n=2)$. Finally, carotid sinus nerve activity was markedly inhibited by the $10^{-3} \mathrm{M}$ Hepes- $\mathrm{Gd}^{3+}$ when the $\mathrm{pH}$ dropped and the inhibition was the same or less after raising the $\mathrm{pH}$ to the normal range. If chemoreceptors were contributing to the response, we may have expected greater inhibition with $\mathrm{Gd}^{3+}\left(10^{-3} \mathrm{M}\right)$ when the $\mathrm{pH}$ was raised to the normal range.

In a recent study by Andresen and Yang (21), $\mathrm{Gd}^{3+}$ had no effect on rat aortic baroreceptors. The reason for the different results is not clear. The contrasting findings may represent a species difference, a difference between aortic and carotid baro-

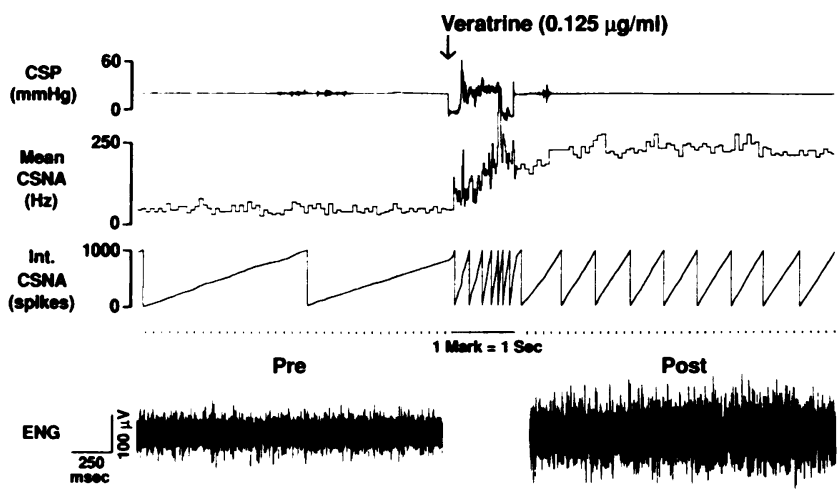

Figure 5. Experimental record showing the increase in carotid sinus nerve activity (CSNA) by veratrine in the presence of $\mathrm{Gd}^{3+}\left(10^{-4} \mathrm{M}\right)$ at constant carotid sinus pressure (CSP). Bottom traces represent electroneurograms $(\mathrm{ENG})$ recorded at fast paper speed before and during exposure to veratrine. Int. CSNA, integrated carotid sinus nerve activity.
A.

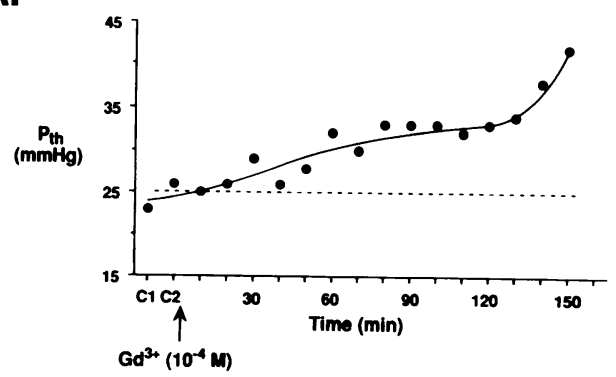

B.
Control

$27 \mathrm{mmHg}$

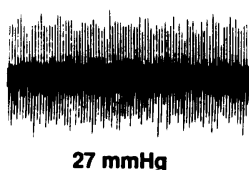

$37 \mathbf{m m H g}$

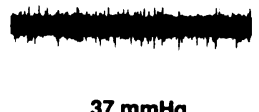

After Gadolinium

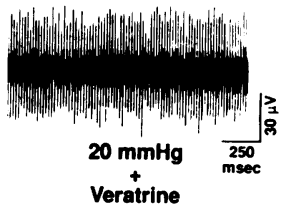

Figure 6. (A) $\mathrm{Gd}^{3+}$ increases the single-unit pressure threshold $\left(\mathrm{P}_{\mathrm{th}}\right)$ from control levels (dashed line) over a period of $150 \mathrm{~min} . \mathrm{C} 1$ and $\mathrm{C} 2$ represent control periods. $(B)$ The addition of veratrine triggered nerve activity of the single fiber at a pressure level $(20 \mathrm{mmHg})$ far below the $\mathrm{P}_{\mathrm{th}}$ of $44 \mathrm{mmHg}$.

receptors, or differences in the preparation or protocols that may have altered the penetrance of $\mathrm{Gd}^{3+}$ into the vessel wall and to the baroreceptor endings. It was necessary to expose the carotid sinus to $\mathrm{Gd}^{3+}\left(10^{-5}-10^{-3} \mathrm{M}\right)$ for prolonged periods averaging close to $1 \mathrm{~h}$ and often up to $2 \mathrm{~h}$ to demonstrate suppression of baroreceptor activity suggesting an apparent barrier to the diffusion of $\mathrm{Gd}^{3+}$. However, with $\mathrm{Gd}^{3+}$ dissolved in the Hepes-buffered salt solution, inhibition of nerve activity was evident within $\sim 30$ min in 9 of 14 experiments. Because of the physical properties and the reactive nature of this particular ionic species (as well as other lanthanides), this may indicate that $\mathrm{Gd}^{3+}$ complexes with other ions more in the bicarbonatebuffered solution, and therefore a longer period of time is necessary to achieve an effective free concentration at the nerve endings. Several investigators have demonstrated an effect of $\mathrm{Gd}^{3+}$ on mechanoelectrical transduction in a variety of cells and preparations, in Xenopus (13), in fungi (15), in canine ventricles (16), in crayfish (12), and in yeast (10). Naruse and Sokabe (18) reported recently that $\mathrm{Gd}^{3+}$ also blocks SA ion channels in endothelial cells. In this study we report that $\mathrm{Gd}^{3+}$ sensitive channels mediate the mechanoelectrical transduction in the carotid sinus baroreceptors. Finally, five classes of SA ion channels have been demonstrated in isolated chick myocytes (23), all of which were blocked by $\mathrm{Gd}^{3+}$. The work by Andresen and Yang (21) may possibly indicate that still a different class of SA ion channels exists on the aortic baroreceptors which is insensitive to $\mathrm{Gd}^{3+}$.

Veratrum alkaloids cause slow inactivation and a shift in the voltage dependence of activation of sodium channels and can generate action potentials at the spike initiation zone where there exists a high density of sodium channels (24-26). Thus, if $\mathrm{Gd}^{3+}$ exerted a nonspecific blockade at the spike zone instead of at the site of mechanoelectrical transduction, we would expect that $\mathrm{Gd}^{3+}$ would block the action of veratrine. The results suggest that $\mathrm{Gd}^{3+}$ blocks the mechanical activation of the baroreceptor but not the effect of veratrine. An effect of veratrine 
on chemoreceptors is excluded by the elimination of chemoreceptor activity in our preparation (see above).

While $\mathrm{Gd}^{3+}$ appears to be a most potent inhibitor of SA ion channels, recent reports have also suggested that other channels may be inhibited by this lanthanide $(27,28)$. Docherty (27) found that $\mathrm{Gd}^{3+}$ at concentrations between 0.5 and $20 \mu \mathrm{M}$ inhibited a calcium current with $\mathrm{N}$-type characteristics in a neuroblastoma-glioma hybrid tumor cell line (NG108-15). In the $\mathrm{GH}_{4} \mathrm{C}_{1}$ pituitary cell line, $\mathrm{Gd}^{3+}$ at concentrations of $50 \mathrm{nM}-5$ $\mu \mathrm{M}$ was found to block $\mathrm{Ca}^{2+}$ current through $\mathrm{L}$ - and T-type channels (28). Thus, a question arises as to the effects of $\mathrm{Gd}^{3+}$ on $\mathrm{Ca}^{2+}$ channels in our preparation.

Several studies have suggested that $\mathrm{Ca}^{2+}$ entry does not play a detectable role in baroreceptor transduction $(29,30)$. Increases in external $\mathrm{Ca}^{2+}$ decrease the excitability of baroreceptors, whereas decreases in external $\mathrm{Ca}^{2+}$ cause an increase in the excitability of baroreceptors, most likely via surface charge effects $(30,31) . \mathrm{Ca}^{2+}$ channel antagonists of the dihydropyridine class either increased (32) or did not alter arterial baroreceptor discharge (29), and the dihydropyridine agonist Bay K8644 also did not affect baroreceptor discharge (30). The increased baroreceptor sensitivity seen with the L-type calcium channel blocker, nifedipine (32), is not consistent with a nonspecific block of $\mathrm{Ca}^{2+}$ channels by $\mathrm{Gd}^{3+}$ in our study, since $\mathrm{Gd}^{3+}$ inhibited rather than sensitized the mechano-responsiveness of the arterial baroreceptors. These observations and the recent report by Naruse and Sokabe (18) indicate that it is unlikely that inhibition of $\mathrm{Ca}^{2+}$ channels by $\mathrm{Gd}^{3+}$ can account for the blockade of the mechanoelectrical transduction mechanism. We therefore conclude that $\mathrm{Gd}^{3+}$ most likely acted to inhibit stretch-activated ion channels in this study. This conclusion is tempered by the recognition that stretch-activated channels have not been demonstrated directly on baroreceptor endings and that mechanoreceptors blocked by $\mathrm{Gd}^{3+}$, not necessarily channels, may trigger action potentials. However, when viewed in the context of all the recent work on mechanotransduction, we believe that our data strongly suggest that stretchactivated ion channels are present on carotid baroreceptor nerve endings and that the opening of these channels, during increases in carotid sinus pressure, is involved in the basic cellular mechanism of activation of the arterial baroreceptors.

\section{Acknowledgments}

We thank Laurie Waite and Krista Wheeler for technical support, Shawn M. Roach for preparation of figures, and Nancy Carter and Amy Oetken for typing the manuscript.

This work was supported by grant HL14388 from the National Heart, Lung and Blood Institute, grant 88-G14 from the American Heart Association, Iowa Affiliate, and research funds from the Department of Veterans Affairs.

\section{References}

1. Brown, A. M. 1980. Receptors under pressure. An update on baroreceptors. Circ. Res. 46:1-10.

2. Arndt, J. O. 1991. Baroreceptors: morphology and mechanics of receptor zones and discharge properties of baroafferents. In Reflex Control of the Circulation. I. H. Zucker and J. P. Gilmore, editors. CRC Press, Inc., Boca Raton, FL. 103-138.

3. Teorell, T. 1971. A biophysical analysis of mechano-electrical transduction. In Handbook of Sensory Physiology. Vol. 1. W. R. Lowenstein, editor. SpringerVerlag, Berlin. 292-339.
4. Kilian, P. L., and J. Schacht. 1980. Sound stimulates labeling of polyphosphoinositides in the auditory organ of the noctiud moth. J. Neurochem. 34:709712.

5. Edwards, C., D. Ottoson, B. Rydqvist, and C. Swerup. 1981. The permeability of the transducer membrane of the crayfish stretch receptor to calcium and other divalent ions. Neuroscience. 6:1455-1460.

6. Brehm, P., R. Kullberg, and F. Moody-Corbett. 1984. Properties of nonjunctional acetylcholine receptor channels on innervated muscle of Xenopus laevis. J. Physiol. (Lond.). 350:631-648.

7. Guharay, F., and F. Sachs. 1984. Stretch-activated single ion channel current in tissue-cultured embryonic chick skeletal muscle. J. Physiol. (Lond.). 352:685701.

8. Morris, C. E. 1990. Mechanosensitive ion channels. J. Membr. Biol. 113:93-107.

9. Sachs, F. 1990. Stretch-sensitive ion channels. Seminars in Neuroscience. 2:49-57.

10. Gustin, M. C., X. L. Zhou, B. Martinac, and C. Kung. 1988. A mechanosensitive ion channel in the yeast plasma membrane. Science (Wash. DC). 242:762-765.

11. Ubl, J., H. Murer, and H. A. Kolb. 1988. Ion channels activated by osmotic and mechanical stress in membranes of opossum kidney cells. J. Membr. Biol. 104:223-232.

12. Erxelben, C. 1989. Stretch-activated current through single ion channels in the abdominal stretch receptor organ of the crayfish. J. Gen. Physiol. 94:10711083.

13. Yang, X. C., and F. Sachs. 1989. Block of stretch-activated ion channels in Xenopus oocytes by gadolinium and calcium ions. Science (Wash. DC). 243:1068-1071.

14. Morris, C. E., and R. Horn. 1991. Failure to elicit neuronal macroscopic mechanosensitive currents anticipated by single-channel studies. Science (Wash. DC). 251:1246-1249.

15. Zhou, X. L., M. A. Stumpf, H. C. Hock, and C. Kung. 1991. A mechanosensitive channel in whole cells and in membrane patches of the fungus Uromyces. Science (Wash. DC). 253:1415-1417.

16. Hansen, D. E., M. Borganelli, C. P. Stacy, Jr., and L. K. Taylor. 1991. Dose-dependent inhibition of stretch-induced arrhythmias by gadolinium in isolated canine ventricles. Evidence for a unique mode of antiarrhythmic action. Circ. Res. 69:820-831.

17. Sigurdson, W., A. Ruknudin, and F. Sachs. 1992. Calcium imaging of mechanically induced fluxes in tissue-cultured chick heart: role of stretch-activated ion channels. Am. J. Physiol. 262:H1110-H1115.

18. Naruse, K., and M. Sokabe. 1993. Involvement of stretch-activated ion channels in $\mathrm{Ca}^{2+}$ mobilization to mechanical stretch in endothelial cells. Am. J. Physiol. 264:C1037-C1044.

19. Hajduczok, G., M. W. Chapleau, and F. M. Abboud. 1988. Rheoreceptors in the carotid sinus of dog. Proc. Natl. Acad. Sci. USA. 85:7399-7403.

20. Xie, P., M. W. Chapleau, T. S. McDowell, G. Hajduczok, and F. M. Abboud. 1990. Mechanism of decreased baroreceptor activity in chronic hypertensive rabbits. Role of endogenous prostanoids. J. Clin. Invest. 86:625-630.

21. Andresen, M. C., and M. Yang. 1992. Gadolinium and mechanotransduction of rat aortic baroreceptors. Am. J. Physiol. 262:H1415-H1421.

22. Snedecor, G. W., and W. G. Cochran. 1980. Statistical Methods, 7th edition. Iowa State University Press, Ames. 215-333.

23. Ruknudin, A., F. Sachs, and J. O. Bustamante. 1993. Stretch-activated ion channels in tissue-cultured chick heart. Am. J. Physiol. 264:H960-H972.

24. Wellhoner, H. H. 1970. The action of veratridine on the membrane potential of the crayfish stretch receptor neurone. Naunyn-Schmiedebergs Arch. Pharmakol. 267:185-188.

25. Barnes, S., and B. Hille. 1988. Veratradine modifies open sodium channels. J. Gen. Physiol. 91:421-443.

26. Wang, G., M. Dugas, B. I. Armah, and P. Honerjager. 1990. Sodium channel comodification with full activator reveals veratridine reaction dynamics. Mol. Pharmacol. 37:144-148.

27. Docherty, R. J. 1988. Gadolinium selectively blocks a component of calcium current in rodent neuroblastoma $\times$ glioma hybrid (NG108-15) cells. $J$. Physiol. (Lond.). 398:33-47.

28. Biagi, B. A., and J. J. Enyeart. 1990. Gadolinium blocks low- and highthreshold calcium currents in pituitary cells. Am. J. Physiol. 259:C515-C520.

29. Kunze, D. L., M. C. Andresen, and L. A. Torres. 1986. Do calcium antagonists act directly on calcium channels to alter baroreceptor function? $J$. Pharmacol. Exp. Ther. 239:303-310.

30. Andresen, M. C., and D. L. Kunze. 1987. Ionic sensitivity of baroreceptors. Circ. Res. 61 (Suppl. 1):I66-I71.

31. Thoren, P., M. C. Andresen, and A. M. Brown. 1982. Effects of changes in extracellular ionic concentrations on aortic baroreceptors with nonmyelinated afferent fibers. Circ. Res. 50:413-418.

32. Heesch, C. M., B. M. Miller, M. D. Thames, and F. M. Abboud. 1983. Effects of calcium channel blockers on isolated carotid baroreceptors and baroreflex. Am. J. Physiol. 245:H653-H661. 